\title{
Lose Yourself in VR: Exploring the Effects of Virtual Reality on Individuals' Immersion
}

\author{
Nane Winkler \\ Technische Universität \\ Darmstadt \\ winkler@ise.tu- \\ darmstadt.de
}

\author{
Konstantin Röthke \\ Technische Universität \\ Darmstadt \\ roethke@ise.tu- \\ darmstadt.de
}

\author{
Nils Siegfried \\ Technische Universität \\ Darmstadt \\ siegfried@ise.tu- \\ darmstadt.de
}

\author{
Alexander Benlian \\ Technische Universität \\ Darmstadt \\ benlian@ise.tu- \\ darmstadt.de
}

\begin{abstract}
Virtual reality (VR) technology generates an interactive virtual environment (VE) creating unique users' experiences. A central part of VR experience is being immersed into a VE. Immersion factors, such as technological and perceptual features, are described in detail in non-immersive VR settings. However, advancements in VR technology, such as head-mounted displays with high resolution and precise motion tracking systems, that improve interactivity within the $V E$ are not yet adequately considered. We conducted twelve semi-structured interviews immediately after respondents played highly immersive games using state-of-the-art VR equipment to identify novel immersion factors in this setting. The findings yield eleven immersion factors across three categories: (1) physical and physiological aspects, (2) cognitive and affective aspects, (3) social interaction and shared experience. Within these categories factors named "shared experience" and "translating actions from physical to virtual reality" were found as novel immersion factors in the VR context.
\end{abstract}

\section{Introduction}

"When you have a task in the game and you can pretty good blend out everything, so, you are just focused with yourself and you are in the game, challenged - you just forget about the outside world."

Virtual reality (VR) allows individuals to experience rich, digitally created worlds that even go beyond what is possible in the real world [3, 19, 39]. Advancements in VR technology, such as headmounted displays in combination with precise motion tracking systems, enables users to experience an interactive three-dimensional (3D) virtual environment
(VE) while communicating and interacting with each other's [16, 31, 54]. A salient aspect that users typically paraphrase when describing their VR experience, is a feeling of being immersed into $\mathrm{VE}$ [e.g., 7, 40]. Immersion describes the extent to which individuals forget about reality and perceive the virtual experience as real $[16,26]$.

Immersive VR technology and the VE created through it, can be used in a variety of contexts such as medical and therapeutic applications [e.g., 4], learning and training [24, 27] or gaming [e.g., 30]. Despite the multitude of application areas, there is no common understanding about what makes VR immersive. While non VR gaming research has identified the design of a VE [e.g., 40] and interaction of avatars [e.g., 8] to increase users' immersion, research in VR and augmented reality (AR) defines physical feedback [e.g., 15, 47] as a main driver for immersion. Taken together in terms of immersion, one stream of literature highlights the importance of the design of and the interaction within a VE [e.g., 8, 40], whereas the other focuses on technological characteristics [e.g., 4]. To reconcile these diverse findings, we heed the call of prior studies to investigate VR immersion to gain a more nuanced understanding of the factors inducing immersion $[25,38,50]$. Therefore, we strive to answer the following research question: What factors affect individual's immersion during the use of an immersive virtual reality?

We conducted twelve semi-structured in-depth interviews in a VR gaming center immediately after respondents played highly immersive games using state-of-the-art VR equipment. The focus was on factors that lead to immersion on an individual's level, which we denote as immersion factors. We identified eleven immersion factors across three main categories. The results of our study contribute to the understanding of individuals' VR immersion and lay the path to more systematic analysis of individuals' VR perception and guidance for designing immersive VR experiences. 


\section{Review: Virtual Reality and Immersion}

An increasing scholarly intention has been paid to immersive technology such as AR and VR [23]. AR enables users to deal with virtual information which is superimposed on the real world [e.g., 15, 47]. VR, in contrast, facilitates a digital created and interactive 3D environment which enables various ways of interaction, collaboration and communication $[16,20]$. Thus, VR technology allows individuals to experience real-world computer environments into which they can immerse themselves [31, 53].

VR can be categorized into non-immersive and immersive VR [34, 49]. Non-immersive VR offers virtual content via a computer screen and thus, exclusively addresses user's senses of seeing and hearing. In contrast, immersive VR enables users to interact through a complex technology system providing visual, acoustic and haptic feedback. Using head-mounted displays (HMD), all visual information from the real world is blocked out leading users to entirely immerse into a VE $[4,34,50]$. Research on immersive VR can be distinguished between VR as a collection of technologies and users' experience within the created VE [41, 49]. This study investigates immersive VR usage and refers to immersive VR when using the term VR.

Research in various fields such as neuroscience, psychology, marketing, entertainment $[4,27,30]$ has demonstrated that VR can be used for medical examinations and therapeutic applications [4], can increase customer learnings about products [27] and enhance gaming experiences [30]. Summarized, through its specific system features, immersive VR provides users exceptional immersive experiences which can be used to amplify individuals' cognitive and affective reactions $[4,33,38]$, such as individuals' anxiety reduction [38], or increasing feelings of anger [33]. The utilization of immersive VR technology has a wide range, from learning and training [e.g., 24] to gaming [e.g., 30].

Researchers have identified sensorimotor contingencies (SC) as a salient system feature of immersive VR [24, 30, 47, 50]. SC describe visual, auditory and haptic feedback, as well as movement tracking [e.g., 15, 47]. Since VR facilitates an interactive $\mathrm{VE}$ with a high degree of media richness, it is able to cause reactions and behavior of individuals that are similar to those in reality $[27,55]$, such as social behavior [55]. Researchers have evaluated different factors understanding users' cognitive reactions evoked through VR usage such as presence and immersion [e.g., 16, 24]. Presence refers to the impression of being in an environment [16]. In conjunction with technological hardware, researchers refer to telepresence. Telepresence is used to describe to which extent individuals feel present in a VE [49]. Immersion determines the "degree to which people perceive that they are interacting with their virtual environment rather than with their physical surroundings" [16:93]. Most studies investigating VR experiences focus on presence [33, 41, 48, 51], whereas immersion has not yet been evaluated in depth using immersive VR [50].

Researcher have shown that immersive VR can evoke various affective and behavioral reactions of users [e.g., 4, 55]. For instance, VR can enhance positive emotions such as fun [e.g., 2], but can also cause negative emotions such as anger [e.g., 32].

\subsection{Immersion as a Psychological Concept}

Immersion is an emotional and cognitive experience, characterized through a lack of awareness for an individual's environment $[16,26]$. Being immersed in something describes the experience of feeling a loss of time, high concentration and total involvement. Immersion has been extensively studied on gamers' playing experience $[6,26,40]$, examining both the conditions under which it emerges and how gamers' experience it [7,37].

Concepts that are related and intertwined to immersion are (1) flow and (2) cognitive absorption. Flow is defined as a process of optimal experience in which individuals are in a state of energized focus and lose their sense for anything except the focal task [14]. First, flow has overlaps with immersion in loss of one's sense of time and offering a challenge that results in task inclusion $[12,26]$. Thus, immersion can be seen as an antecedent to flow [26]. Second, cognitive absorption (CA) is characterized in information systems (IS) research as a condition of profound participation and involvement with software. Rooted in technology acceptance research, it is used to better understand individuals' reactions towards information technology. Thus, CA describes individual's attitude [1]. In contrast, immersion refers to a concrete experience of individuals [26].

Immersion is a complex condition of an individual's mind and a multi-faced process. Describing immersion, researchers define different features and evaluate immersion based on different concepts and levels [7, 18, 24, 26, 50]. Jennett et al. [26] describe a feeling of losing track of time, a decreased sense of the real world and the involvement and ability to be in the task environment as specific immersion features. Levels of immersion are engagement, engrossment and total immersion which examine gamer's decreased connection to the real world and an increase of psychological and physical 
involvement with the virtual world [7]. Researchers also distinguish between physical and mental immersion [46]. Physical immersion is caused through visual, auditory and haptic cues in a virtual environment whereas mental immersion refers to the degree of engagement within a VE [46].

Immersion has been researched in traditional computer games [e.g., 7, 26] or using the concept of augmented reality [e.g., 18, 51]. However, yet little is known about which facets of immersion are salient in a VE created by an immersive VR with sophisticated hardware such as a head mounted display (HMD) and motion tracking.

\subsection{Immersion in Virtual Reality}

Despite growing scholarly attention to immersive technologies like VR, there is no common understanding which factors affect individual's immersion as research conceptualizes immersion differently [18, 24]. However, having a clear conceptualization and operationalization of key factors that describe users' perception of technological features and cognitive responses towards VR is vital for practice and academia. Understanding what constitutes immersion, can contribute for example to users' training transfer, to enhance users' performance and experiences $[5,25,50]$.

Two major themes emerge from prior literature: first, immersion is described as a multi-layered process with diverse contributing concepts [e.g., 7, 25, 46] and second, VR research falls short of providing a holistic approach on immersion both in terms of evaluation methods and describing users' experience [e.g., 36, 50]. These shortcomings are surprising as immersion is crucial to the concept of VR, which becomes apparent in the definition as "the medium able to induce the experience of presence in a computer-generated world" [41:46].

Through VR-specific features such as visual, auditory and haptic feedback, individuals are able to experience a VE as if they were part of - i.e. be immersed into the VE [50]. Previous research has tapped into the relationship between isolation from the real world and players' perceived immersion [7]. However, no comprehensive set of VR immersion factors has yet been presented [e.g., 22, 50].

Scholars from other research fields have defined some factors that can enhance individuals' immersion $[4,17,25,40]$. In neuroscience, sensorimotor features such as visual stimuli, sound effects and natural body movements have been evaluated to increase individuals' immersion while using VR [4]. In entertainment research, scholars outline a game's narrative to be important to create immersion during computer gaming [40]. Moreover, education research identifies interactive media as an immersion enhancing factor [17]. However, research has focused solely on these specific and isolated immersion factors. Further, gaming and VE research provide diverse overlapping definitions of users' immersion and captured it in related constructs such as flow and presence $[10,21$, 22].

While isolated insights into immersion factors exist [e.g., 4, 17, 40], a holistic understanding of what exactly facilitates and what hinders individuals' immersion into VR is missing. Only few studies have evaluated VR immersion factors in depth [e.g., 25, 28, 36]. In the study of Hudson et. al [25], virtual experiences in leisure and tourism are investigated. The researchers examine person- $\mathrm{VE}$ interaction as an influencing factor of users' VR immersion using an immersive underwater VR experience [25]. Kim et al. [28] investigate users' level of immersion on emotional responses while watching a movie using HMD vs. NoHMD and horror vs. empathy content. They have demonstrated that users' level of immersion is dependent to the degree of arousal and perceptual cues [28].

Transferring the findings of general immersion affecting physical and psychological features in the context of VR, the following concepts emerge as potential VR immersion factors: visual, auditory and haptic feedback, users' cognitive and affective reactions and bodily changes. As VR is an interactive 3D environment which can foster individuals' interaction, collaboration and communication $[16,20]$, it is important to also include these concepts as potential immersion factors [e.g., 8, 36]. Nevertheless, these are only theoretically relevant concepts, which have not been systematically evaluated in VR users' perceptions. By exploring aspects of VR experiences, we aim to understand which features of VR technology actually affect users' immersion and to gain a better understanding of the underlying psychological processes.

\section{Research Methodology}

To answer our research question, we have conducted and analyzed semi-structured interviews with players in a VR gaming center offering room scale VR experience through the SteamVR platform (Valve, Bellevue, WA, USA) in single player or local multiplayer mode with up to 6 players. The VR gaming areas $(3 \times 3 \mathrm{~m})$ were equipped each with a state-of-theart gaming computer and a Vive Pro Full Kit (HTC, New Taipeh, Taiwan) consisting of an HMD with integrated headset and microphone, two wireless 
controllers and two SteamVR 2.0 Lighthouse base stations for precise motion tracking. The center management granted the authors entry to their facilities for conducting fieldwork and encouraged customers to participate in interview sessions thereby giving credibility and legitimacy to the research.

We transcribed each interview, systematically coded the responses and derived a set of analytical VR immersion categories. Considering both, the nascent stage of knowledge regarding immersion in VR and the more advanced understanding in related fields, a research approach was chosen that enables incorporating prior related theory, but also allows for explicit pre-assumptions [45]. We prepared an interview guideline with predefined themes of SCs, interaction, challenge, focused attention, flow, and emotional involvement, which were mainly based in related gaming and VR literature [e.g., 26, 47]. The questions were relatively flexible regarding sequence and emphases of themes. Each theme was introduced with open-ended questions to encourage respondents to narrate on their experiences. Exemplary interview questions are presented in appendix A.

After transcribing the material, a four stage analytical strategy according to Schmidt [45] was developed and applied to retrieve the concepts embedded in the collected material. At the core, this strategy helps to identify initial concepts and link them to higher-level categories [9]. This procedure has been previously used in qualitative interpretative IS research [e.g., 43, 44, 52] and comprises of four stages, which we present in the following paragraphs:

First, categories for the analysis are formed by thoroughly reading through all transcripts, marking aspects broadly related to the research question [45]. In the initial coding cycle, we use a descriptive coding approach, which summarizes the basic topic of a passage. In a subsequent coding cycle, we employ pattern coding to identify category labels and develop major themes, rules and explanations from the data [42]. In an interchange process, these topics and categories are contrasted to ideas for categories developed prior to data collection and finally condensed into analytical categories.

Second, these categories are arranged into an analytical coding guide, by providing descriptions and versions for each category [13]. In the process of testing the guide with a number of interviews it is further refined and rearranged if necessary. The guide was refined until no new category emerged and a convergence towards the analytical categories used in the final coding guide was achieved.

Third, the material is coded in accordance to the coding guide such that the material is classified and phrases are assigned to the different previously developed categories.

Finally, after coding the material, detailed case interpretations are performed [45]. For example, a specific category is analyzed in depth by comparing selected transcripts. This final stage commonly uses an interpretive and inductive approach. To account for variations arising from subjective assessment of three different researchers during the coding process, we calculated Cohen's kappa coefficient to measure interrater agreement. The cross-coding of one interview transcript resulted in a Cohen's kappa $\kappa=0.767$, which indicates substantial agreement $[11,29]$.

The study was initialized in February 2019, featuring data collection from two interview sessions over the period of two months. In total, we interviewed 12 respondents (R1-R12) at the VR game center, immediately after their VR gaming experience. Each participant had played at least one game for 30 minutes and played at least once together with other players in multiplayer mode. The average duration of the interviews was 20:03 minutes with the shortest interview being 09:47 minutes and the longest interview being 26:28 minutes. Half of the twelve subjects were females and the other half males. Participants exhibited an average age of 25.6 years and typically stated they had only moderate or no prior VR usage experience.

\section{Analyses and Results}

Over all, three broad categories of immersion are illuminated in our study: (1) physical and physiological aspects, (2) cognitive and affective aspects, (3) social interaction and shared experience. Further, we identified eleven immersion factors which we assigned to these three categories (Table 1).

\subsection{Physical and Physiological Aspects}

A characteristic of immersive VR which distinguishes it from other immersive technologies, is the inclusion of at least three senses leading to an isolation from the real world. Since this unique feature compels user's attention to some degree, it is potentially an important precondition favoring subsequent cognitive inclusion.

Visual and auditory inclusion: A particular salient characteristic of immersive VR is the visual and auditory inclusion of users. The HMD blocks the entire field of view and the integrated headphones obstruct the sense of hearing. As a result, the VR user can only see and hear what is part of the VE and can therefore 
easily focused on what is happening in the artificial environment. R1 described the following experience:

"And because you just have headphones and these glasses, you dive in completely and you don't perceive the outside world. So, you hardly hear anything, even if the sounds come from the room, which happens only in very rare times, so that you are completely isolated. What's good for the focus, is that you can concentrate completely on the game."

Translating actions from physical to virtual reality: We identified a unique feature of immersive VR distinguishing it from different human computer interaction. R7 explained exercising this aspect of VR:

"[...] that you move your head, so that the whole is responsively moving along. The screen always keeps moving and that is definitely all three-dimensional, what is going on there."

This perceptual quality of VR was described as SC. It can be used to characterize immersive systems and refer to its ability to represent and translate the movements and actions performed in physical reality into VR [48]. Examples for SCs are the movement of the visuals displayed in the HMD in accordance to the movement of a user's head and eyes to change gaze direction, or triggering of events when users move or press buttons on their controllers.

R8 further elaborated on SCs and described experiencing physical activity in VR and compared it to the corresponding action in real world:

"You had two remote controls in your hand and could then draw the bow and shoot, just like you would do it in real life, you know the physical movement."

$\mathrm{R} 8$ also explained how important this feature is while experiencing VR:

"I think it important that you are physically active somehow. And it's very important that you engage in the movement and that it is also somewhat cognitively demanding."

Transportation: A phenomenon connected to perceptual inclusion and SC in immersive VR is transportation. It refers to cognitive state that induces a feeling of being separated from the real world [26]. The experience in the VR is sometimes so intense that interviewees forget that they are wearing HMDs and using controllers. In the interview with R10 we retrieved this description:

"Well, I noticed it at the end, when it was over, that I actually have some glasses on, and meanwhile, when there is a lot of action in the game, then I totally forgot that I had glasses on."

Distracting aspects of VR usage: Despite the interviewees' descriptions analyzed so far, there were some aspects of VR usage, which were sources of distraction impairing the VR experience. Some respondents experienced motion sickness, which occurs when different sense organs provide contradictory information about the spatial position and movement of the body. In our context, it occurred only when respondents were playing an action game which involved walking. In this case the sense of sight provides contradictory information compared to the vestibular system which provides information about spatial orientation and acceleration.

However, most of the interviewees were distracted by the way the hardware was attached to their head. The HMD was wired via a cable which was ducted to the ceiling of the room. Although, this cable arrangement prevented interviewees from stumbling over it, it obstructed their freedom of movement. Furthermore, after some time of using the HMD interviewees sweat underneath the glasses, which also distracted them from experiencing the VR. R8 described this situation in the following way:

"I think the game was very engaging, it was more technical stuff, that the glasses slipped and then you couldn't see properly, that you had to correct it. Or once it got incredibly warm while playing. Or that somehow the cable was too short. Well, you can move relatively freely, but you always notice okay, there's something on my head right now that pulls. So I think that is always a bit distracting."

\subsection{Cognitive and Affective Aspects}

An important aspect of immersion is found in having a strong focus and concentration on the VR. This focus has two components: (1) getting pulled into and engaged with the virtual world while (2) being isolated and separated from the real world. In this section, we focus on the first component.

Concentrated attention: It was mentioned by multiple interviewees that the games took their full attention. R1 explained:

"Maybe in the first minutes you have some thoughts on what you need to do tonight but after that: nothing. There was only the game in my focus."

This high level of focus, however, was not experienced as being overwhelming or overcharging. Quite the contrary, interviewees reported that they liked to be fully engaged with the VR and unequivocally stated that they experienced playing the games as fun. In this regard, R2 stated that:

"[...] you are concentrated and then you get into this flow."

During extended play, some games were adaptive to the capabilities of the interviewees. This was mentioned important, as an adaptive level of challenge kept high focus. Contrary, when the game did not adapt, interviewees became better and were no longer 
challenged enough leading to a perception of the game becoming boring over time as mentioned by $\mathrm{R} 1$ :

"The types of enemies that you know lose some thrill, you know them and you know exactly how to fight them and so you just go on."

Losing sense of time: Indicating the high level of focus and attention, interviewees reported unequivocally that their sense of time changed when playing. Being engaged in the VR, they lost track of how much time had passed. For instance, R1 mentioned:

"I was totally surprised that a full hour was already gone”.

Reflecting back on their playing time, the majority reported that it felt shorter than it actually was. Moreover, R10 stated that she would have played longer if not being interrupted by the end of the session:

"I would definitively, I mean if the session had not been over, I would have stayed with the game, probably even if I had committed to stop at that time before."

Affective involvement: The engagement with the VR was not only experienced cognitively but also emotionally. Interviewees were emotionally involved in playing, especially in relation to their own success or failures. For instance, R3 felt "[...] angry when I died [...]", while feeling "[...] pleased when I fired arrows, which flew very far and still hit the enemies [...]" playing an archer in a tower defense game. Besides, affective reactions were triggered in surprising situations and when confronted with new challenges. R1 explained:

"There were these dogs that really scared me when they came around the corner. When it comes unexpected, you can get pretty frightened".

However, regarding emotional depth interviewees criticized that the experience was not on par with reality or other forms of audiovisual entertainment (e.g., blockbuster movie productions or video games). R12 explained:

"When playing regular video games, it is more about getting to know the characters, getting immersed in the story. But here it felt more anonymous, because this is missing. It works more about the visual aspect."

The missing depth and complexity of the experience was also mentioned by R1:

"I can imagine that when you play longer it abates [...]. The game concept is still pretty simple."

This underscores that the technological aspects of VR do not induce affective responses per se. It rather depends on the emotional involvement that is facilitated by a concrete VR setting.

Control: An important antecedent to both focus and affective reaction was given by interviewee's level of control over their interaction with VR. Having no control can quickly lead to decreased attention and low involvement as, for instance described by R11:

"Sometimes you had to wait for the next level, it became boring. Because you could collect points and then all were gone and we just had to wait until it finally continued."

A medium level of control, in which the player knew roughly what to do but could make individual choices was appreciated, R1 reported:

"You are not that free that you can get totally lost, it is more that the ways are determined with some options to choose and that was pretty good."

\subsection{Social Interaction and Shared Experience}

The concept of interactive media has been investigated in other research fields like education and gaming as an immersion enhancing factor [8, 17]. However, VR research has not yet examined in depth how interaction in VEs can affect user's immersion. Our study revealed three subcomponents of this dimension of immersion factors.

Interaction between users: For most respondents it was a decisive factor whether they played with other individuals in a VR game. R8 described the following situation:

"The interaction is intensified by the other players, because you exchange information about the game."

Further, R10 mentioned in this context getting immersed is more easily if they played together:

"There were two of us and so the effect of being in the game was intensified."

One interviewee held the position that the gaming sector merely produces single-player games and that multi-player mode may be the future of gaming (R4). Furthermore, many of the respondents claimed that the social interaction in the virtual world was very important for whether they had fun and found the game appealing. Another aspect important to some interviewees, was teamwork within the game. R1 expressed this feeling with the following statement:

"The teamwork was really great and I enjoyed it."

Some of the interviewees explained that they had to tactically coordinate themselves in order to progress in the game. R3 even emphasized the increased cooperation through the interaction compared to nonVR games.

Perception of other avatars: In multi-player games, the perception of other players was important for the interviewees and contributed significantly to their gaming experience. Some of the interviewees positively mentioned that they saw their fellow players 
and were able to communicate with them, i.e. they could hear and talk to each other.

However, some found it difficult to identify the avatars as they missed a personal touch. R10 described the following situation:

"If you play a board game you actually have a counterpart, whereas VR games are missing that because you perceive more about voices."

In the course of the interviews, a great disadvantage of VR games was identified: the representation of the players in the game. Currently, there is only a shadowy representation of the fellow players. The avatars are only hinted (e.g. through different colored armor) and hardly differ from each other. For some of the interviewees this impedes immersion as avatars have lacked facial expressions. Hence, some interviewees found the game impersonal and unreal, and R10 stated:

"The face of the avatar is missing completely, but the representation of a face would be enough to strengthen the gaming experience."

Shared experience: Another important factor, which was examined during the interviews, is shared experience of the players. Some of the interviewees found that such a shared experience brings them closer together and increases the fun factor. R1 said:

"I thought it was really good, as you can go ahead as a team. You coordinate yourself and thus, have much better chances. This circumstance makes it much more fun."

One interviewee said that the gaming experience goes beyond the game, which means that afterwards you can exchange ideas about how you could have cooperated better (R1). Furthermore, R10 mentioned that a shared experience helps to get into the game:

"When someone else has experienced the very same thing, you get more immersed in the game."

Table 1. Immersion factors in VR

\begin{tabular}{|l|l|}
\hline Category & Predictor of immersion \\
\hline \multirow{4}{*}{$\begin{array}{l}\text { Physical and } \\
\text { physiological aspects }\end{array}$} & $\begin{array}{l}\text { Visual and auditory } \\
\text { inclusion }\end{array}$ \\
\cline { 2 - 2 } & $\begin{array}{l}\text { Translating actions from } \\
\text { physical to virtual reality }\end{array}$ \\
\cline { 2 - 2 } & Transportation \\
\cline { 2 - 2 } & $\begin{array}{l}\text { Distracting aspects of } \\
\text { virtual reality }\end{array}$ \\
\hline \multirow{4}{*}{$\begin{array}{l}\text { Cognitive and } \\
\text { affective aspects }\end{array}$} & Concentrated attention \\
\cline { 2 - 2 } & Losing sense of time \\
\cline { 2 - 2 } & Affective involvement \\
\cline { 2 - 2 } Social interaction and & Control \\
\hline \multirow{2}{*}{ shared experience } & Interaction between users \\
\cline { 2 - 2 } & Perception of other avatars \\
\cline { 2 - 2 } & Shared experience \\
\hline
\end{tabular}

\section{Discussion}

In this study, we identified eleven immersion factors across three categories (Table 1) that constitute to individuals' immersion using VR. The categories are (1) physical and physiological aspects, (2) cognitive and affective aspects, and (3) social interaction and shared experience. Hence, our results support the conjecture from prior research that immersion is a multi-layered process [e.g., 7, 8, 46].

Nine out of eleven immersion factors that we identified are already described in previous research: "visual and auditory inclusion" [e.g., 47, 50], "transportation" [e.g., 7], "distracting aspects of virtual reality" [e.g., 35], "concentrated attention" [e.g., 26], "losing sense of time" [e.g., 26], "affective involvement" [e.g., 2, 32], "control" [e.g., 26], "interaction between users" [e.g., 25] and "perception of other avatars" [e.g., 50]. Additionally, we have identified "shared experience" and "translating actions from physical to virtual reality" as novel immersion factors in the VR context.

Our findings contribute to theory and practice by enhancing our understanding of immersion in VR using HMD and motion tracking. While increased attention is paid to VR in academia and practice [4, 50], little is known about what constitutes individuals' immersion. However, immersion plays a key role in understanding users' motivation and usage intentions. Immersion goes beyond the mere technical aspect of VR and includes users' perceptions as well as the VR setting. The more we understand what makes individuals "dive into VR", the better we can design VR experiences and identify potential hindrances in its current application. There are four major contributions from our results:

First, our study contributes to previous work, which suggests that increasing SC enhance individual's immersion [4]. If users are physically challenged by immersive VR, they are more immersed in the virtual environment. Thus, feedback seem to be decisive factors in users' VR immersion. Moreover, users' movement within the VE came up as a decisive factor being immersed in VR.

Second, our study finds support that individuals' cognitive and affective aspects also increase immersion $[7,26]$. Furthermore, interviewees explained that they enjoy to be focused and immersed rather than being stressed by the technology. This condition enlightens a focused and concentrated work with technology in a completely different light. However, as the participants were recruited in a VR gaming center, a selection bias cannot be excluded.

Third, we shed light on the controversially discussed topic of social interaction. Some researchers 
indicate that playing together decreases individuals' immersion, whereas others claim that social interaction during the game experience enhances individuals' immersion [8]. We find support that social interaction between users and perception of other user's avatars are relevant for immersion.

Forth we identified two novel immersion factors in the context of immersive VR: "shared experience" and "translation actions from physical to virtual reality". The latter immersion factor is highly connected to the advancements in VR technology, especially the precise motion tracking system allowing interactivity with objects in the VE in the same way as in the physical environment. In contrast "shared experience" can also occur in non-immersive VR settings with multiplayer mode.

Besides, the results also revealed distracting aspects such as troublesome technical equipment. Further, the shadowy representation of the avatars hinders users' immersion, as the VR game is perceived unrealistically and impersonally.

The results of this study are useful to future research as they provide a good foundation for more fine-grained analysis of immersion factors in the VR context. Moreover, practitioners may benefit from using the factors as a guidance to improve their offerings in regard to users' immersion.

This study has several limitations that should be considered when applying its findings. The interviewees are not representative as only a random selection was made. In addition, using a semistructured interview guide may lead to a unilateral focus so that certain aspects contributing important immersive factors might have been overseen. Also, users were asked about their personal opinions, so that our findings are limited in their validity. We used this approach to conduct preliminary work for quantitative studies. Due to space constraints, only a limited selection of participants' phrases could be elaborated on in detail. Finally, due to the exploratory approach of our study design, we were not able to reliably distinguish between factors and predictors of immersion.

Future research may go beyond these limitations and extend our findings by conducting quantitative research looking into the relative importance and the possible interaction of the identified factors and their validation across a larger sample of VR users.

\section{Acknowledgments}

We thank Hannah Griesbaum and Andreas Koch (VR Lighthouse, Mannheim, Germany) for the opportunity to conduct our research in their facilities and encouraging their customers to take part in this study.

\section{References}

[1] Agarwal, R., and E. Karahanna, "Time Flies When You're Having Fun: Cognitive Absorption and Beliefs About Information Technology Usage", MIS Quarterly 24(4), 2000, pp. 665-694.

[2] Alelis, G., A. Bobrowicz, and C.S. Ang, "Comparison of engagement and emotional responses of older and younger adults interacting with 3D cultural heritage artefacts on personal devices", Behaviour \& Information Technology 34(11), 2015, pp. 1064-1078.

[3] Blascovich, J., J. Loomis, A.C. Beall, K.R. Swinth, C.L. Hoyt, and J.N. Bailenson, "Immersive Virtual Environment Technology: Just Another Methodological Tool for Social Psychology?", Psychological Inquiry 13(2), 2002, pp. 146149.

[4] Bohil, C.J., B. Alicea, and F.A. Biocca, "Virtual Reality in Neuroscience Research and Therapy", Nature Reviews. Neuroscience 12(12), 2011, pp. 752.

[5] Bowman, D.A., and R.P. McMahan, "Virtual Reality: How Much Immersion Is Enough?", Computer 40(7), 2007, pp. 36-43.

[6] Brockmyer, J.H., C.M. Fox, K.A. Curtiss, E. McBroom, K.M. Burkhart, and J.N. Pidruzny, "The development of the Game Engagement Questionnaire: A measure of engagement in video game-playing", Journal of Experimental Social Psychology 45(4), 2009, pp. 624-634.

[7] Brown, E., and P. Cairns, "A Grounded Investigation of Game Immersion", Proceedings of ACM CHI 2004 Conference on Human Factors in Computing Systems, ACM Press (2004), 1297-1300.

[8] Cairns, P., A.L. Cox, M. Day, H. Martin, and T. Perryman, "Who but not where: The effect of social play on immersion in digital games", International Journal of Human-Computer Studies 71(11), 2013, pp. 1069-1077.

[9] Charmaz, K., R. Thornberg, and E. Keane, "Evolving Grounded Theory and Social Justice Inquiry", In N.K. Denzin and Y.S. Lincoln, eds., The SAGE Handbook of Qualitative Research. SAGE Publications, Thousand Oaks, CA, 2017, 720-776.

[10] Christou, G., "The interplay between immersion and appeal in video games", Computers in human behavior 32, 2014, pp. 92-100.

[11] Cohen, J., "A coefficient of agreement for nominal scales", Educational and Psychological Measurement 20(1), 1960, pp. 37-46.

[12] Cowley, B., D. Charles, M. Black, and R. Hickey, "Toward an understanding of flow in video games", Computers in Entertainment (CIE) 6(2), 2008, pp. 1-27. 
[13] Crabtree, B.F., and W.F. Miller, "A template approach to text analysis: developing and using codebooks.", 1992.

[14] Csikszentmihalyi, M., S. Abuhamdeh, and J. Nakamura, "Flow", In M. Csikszentmihalyi, ed., Flow and the Foundations of Positive Psychology. Springer, Dordrecht, 2014, 227-238.

[15] Datcu, D., S. Lukosch, and F. Brazier, "On the usability and effectiveness of different interaction types in augmented reality", International Journal of Human-Computer Interaction 31(3), 2015, pp. 193-209.

[16] Davis, A., J. Murphy, D. Owens, D. Khazanchi, and I. Zigurs, "Avatars, people, and virtual worlds: Foundations for research in metaverses", Journal of the Association for Information Systems 10(2), 2009, pp. 90-117.

[17] Dede, C., "Immersive Interfaces for Engagement and Learning”, Science 323(66), 2009, pp. 68.

[18] Georgiou, Y., and E.A. Kyza, "The development and validation of the ARI questionnaire: An instrument for measuring immersion in location-based augmented reality settings", International Journal of Human-Computer Studies 98, 2017, pp. 24-37.

[19] Gillath, O., C. McCall, P.R. Shaver, and J. Blascovich, "What can virtual reality teach us about prosocial tendencies in real and virtual environments?", Media Psychology 11(2), 2008, pp. 259-282.

[20] Gilson, L.L., M.T. Maynard, N.C. Jones Young, M. Vartiainen, and M. Hakonen, "Virtual Teams Research: 10 Years, 10 Themes, and 10 Opportunities", Journal of Management 41(5), 2015, pp. 1313-1337.

[21] Goel, L., N. Johnson, I. Junglas, and B. Ives, "Predicting users' return to virtual worlds: a social perspective", Information Systems Journal 23(1), 2013, pp. 35-63.

[22] Grinberg, A.M., J.S. Careaga, M.R. Mehl, and M.-F. O'Connor, "Social engagement and user immersion in a socially based virtual world", Computers in Human Behavior 36, 2014, pp. 479-486.

[23] Handa, M., G. Aul, and S. Bajaj, "Immersive technology-uses, challenges and opportunities", International Journal of Computing \& Business Research 6(2), 2012, pp. 1-11.

[24] Huang, H.-M., U. Rauch, and S.-S. Liaw, "Investigating learners' attitudes toward virtual reality learning environments: Based on a constructivist approach", Computers \& Education 55(3), 2010, pp. 1171-1182.

[25] Hudson, S., S. Matson-Barkat, N. Pallamin, and G. Jegou, "With or without you? Interaction and immersion in a virtual reality experience", Journal of Business Research 100, 2019, pp. 459-468.

[26] Jennett, C., A.L. Cox, P. Cairns, et al., "Measuring and defining the experience of immersion in games",
International Journal of Human-Computer Studies 66(9), 2008, pp. 641-661.

[27] Kil-Soo Suh, and Young Eun Lee, "The Effects of Virtual Reality on Consumer Learning: An Empirical Investigation", MIS Quarterly 29(4), 2005, pp. 673-697.

[28] Kim, A., M. Chang, Y. Choi, S. Jeon, and K. Lee, "The Effect of Immersion on Emotional Responses to Film Viewing in a Virtual Environment", 2018 IEEE Conference on Virtual Reality and $3 D$ User Interfaces (VR), (2018), 601602 .

[29] Landis, J.R., and G.G. Koch, "The measurement of observer agreement for categorical data", Biometrics 33(1), 1977, pp. 159-174.

[30] Lee, H.-G., S. Chung, and W.-H. Lee, "Presence in virtual golf simulators: the effects of presence on perceived enjoyment, perceived value, and behavioral intention", New Media \& Society 15(6), 2013, pp. 930-946.

[31] Li, H., T. Daugherty, and F. Biocca, "Characteristics of virtual experience in electronic commerce: A protocol analysis", Journal of Interactive Marketing 15(3), 2001, pp. $13-30$.

[32] Lin, J.-H.T., "Fear in virtual reality (VR): Fear elements, coping reactions, immediate and next-day fright responses toward a survival horror zombie virtual reality game", Computers in Human Behavior 72, 2017, pp. 350-361.

[33] Lull, R.B., and B.J. Bushman, "Immersed in Violence: Presence Mediates the Effect of 3D Violent Video Gameplay on Angry Feelings", Psychology of Popular Media Culture 5(2), 2016, pp. 133-144.

[34] Mills, S., and J. Noyes, "Virtual reality: an overview of User-related Design Issues Revised Paper for Special Issue on 'Virtual reality: User Issues' in Interacting With Computers, May 1998”, Interacting with Computers 11(4), 1999, pp. 375-386.

[35] Munafo, J., M. Diedrick, and T.A. Stoffregen, "The virtual reality head-mounted display Oculus Rift induces motion sickness and is sexist in its effects", Experimental Brain Research 235(3), 2017, pp. 889-901.

[36] Mütterlein, J., and T. Hess, "Immersion, Presence, Interactivity: Towards a Joint Understanding of Factors Influencing Virtual Reality Acceptance and Use", Proceedings of the 23rd Americas Conference on Information Systems, (2017).

[37] Nacke, L.E., S. Stellmach, and C.A. Lindley, "Electroencephalographic assessment of player experience: A pilot study in affective ludology", Simulation \& Gaming 42(5), 2011, pp. 632-655.

[38] Parsons, T.D., and A.A. Rizzo, "Affective outcomes of virtual reality exposure therapy for anxiety and specific phobias: A meta-analysis", Journal of behavior therapy and experimental psychiatry 39(3), 2008, pp. 250-261. 
[39] Persky, S., and J. Blascovich, "Immersive Virtual Environments versus Traditional Platforms: Effects of Violent and Nonviolent Video Game Play", Media Psychology 10(1), 2007, pp. 135-156.

[40] Qin, H., P.-L. Patrick Rau, and G. Salvendy, "Measuring player immersion in the computer game narrative", International Journal of Human-Computer Interaction 25(2), 2009, pp. 107-133.

[41] Riva, G., F. Mantovani, C.S. Capideville, et al., "Affective Interactions Using Virtual Reality: The Link between Presence and Emotions", CyberPsychology \& Behavior 10(1), 2007, pp. 45-56.

[42] Saldaña, J., The Coding Manual for Qualitative Researchers, SAGE Publications, Thousand Oaks, CA, 2009.

[43] Sarker, S., and S. Sarker, "Exploring agility in distributed information systems development teams: An interpretive study in an offshoring context", Information Systems Research 20(3), 2009, pp. 440-461.

[44] Sarker, S., S. Sarker, and A. Sidorova, "Understanding business process change failure: An actor-network perspective", Journal of management information systems 23(1), 2006, pp. 51-86.

[45] Schmidt, C., "The Analysis of Semi-structured Interviews", In U. Flick, E. von Kardorff and I. Steinke, eds., A Companion to Qualitative Research. SAGE Publications, Thousand Oaks, CA, 2004, 253-258.

[46] Sherman, W.R., and A.B. Craig, Understanding virtual reality: Interface, application, and design, Morgan Kaufmann, Cambridge, MA, 2018.

[47] Slater, M., "Place illusion and plausibility can lead to realistic behaviour in immersive virtual environments", Philosophical Transactions of the Royal Society B: Biological Sciences 364(1535), 2009, pp. 3549-3557.

[48] Slater, M., B. Lotto, M.M. Arnold, and M.V. SánchezVives, "How we experience immersive virtual environments: the concept of presence and its measurement", Anuario de Psicología 40(2), 2009, pp. 192-210.

[49] Steuer, J., "Defining Virtual Reality: Dimensions Determining Telepresence", Journal of Communication 42(4), 1992, pp. 73-93.

[50] Suh, A., and J. Prophet, "The state of immersive technology research: A literature analysis", Computers in Human Behavior 86, 2018, pp. 77-90.

[51] Von der Pütten, A.M., J. Klatt, S. Ten Broeke, et al., "Subjective and behavioral presence measurement and interactivity in the collaborative augmented reality game TimeWarp", Interacting with Computers 24(4), 2012, pp. 317-325.
[52] Walsham, G., "Doing interpretive research", European Journal of Information Systems 15(3), 2006, pp. 320-330.

[53] Wexelblat, A., ed., Virtual Reality Applications and Explorations, Academic Press, San Diego, CA, 1993.

[54] Yee, N., and J. Bailenson, "The Proteus Effect: The Effect of Transformed Self-Representation on Behavior", Human Communication Research 33(3), 2007, pp. 271-290.

[55] Yee, N., J.N. Bailenson, M. Urbanek, F. Chang, and D. Merget, "The unbearable likeness of being digital: The persistence of nonverbal social norms in online virtual environments", CyberPsychology \& Behavior 10(1), 2007, pp. $115-121$

\section{Appendix A. Sample excerpt from the interview guideline}

1. What did/didn't you like about the VR game?

a) How long did you play the game?/Did the time seem shorter or longer to you or did you lose your sense of time completely?/Did you want to take off your glasses at any time to see what was happening in reality?

b) Have you played the game before?

c) Did you play the game with others?

2. What exactly has created immersion in you and why?

3. How did you feel while playing?

a) Have you suffered motion sickness?

b) How far would you say the game feels real?

c) What makes the experience real?

d) But how does it differ from your reality?

4. To what extent did you feel like you were really in the game?

a) How did you notice that?/Have you had to devote all your attention and concentration to playing?/Did it feel like you were separated from the real world?/Have you ever forgotten that you are using a controller/HMD?

b) Does the game feel real to you?/What would have to be different for it to feel real to you?/In comparison with a real game like football - what is missing in VR?

5. How actively could you steer the game?

a) What is the level of interaction when playing?

b) To what extent could you control the game?

6. Did you find the game rather too easy or too hard?

a) How did you notice that?

b) Did the game motivate you and did you have the feeling that you are getting better?

c) What would you have to change to make it fit you better?

7. Were there situations in which you felt unexpectedly positive/neutral/negative feelings (e.g., joy, enthusiasm, excitement, fear, anxiety)? 